\title{
Optimization of Alkali Pretreatment Conditions for Wax Removal from Bamboo Culm
}

\author{
Jong-Bum Ra, ${ }^{\mathrm{a}}$ Jeong-Joo Oh, ${ }^{\mathrm{b}}$ and Gyu-Hyeok Kim ${ }^{\mathrm{b}, *}$
}

\begin{abstract}
Appropriate chemical reagents were selected for removing the wax layer of bamboo culm, and optimal treatment conditions with the selected agents were determined in this study. Solutions of potassium carbonate, potassium hydroxide, sodium carbonate, and sodium chloride, along with their mixtures with $1 \%$ sodium dodecyl sulfate, were tested for efficacy of wax removal on culms of giant timber bamboo (Phyllostachys bambusoides S. et Z.), hachiku bamboo (Phyllostachys nigra var. henosis Stapf), and moso bamboo (Phyllostachys pubescens Mazel). Of the tested reagents, the mixture of potassium hydroxide and sodium dodecyl sulfate showed the best capability. The effects of varying concentrations of the selected reagents and reaction times at $90{ }^{\circ} \mathrm{C}$ were investigated by response surface methodology (RSM). Quadratic regression models representing the degree of wax removal at various treatment conditions were determined. The coefficients of determination of the fitted models were greater than 0.98 , meaning that the models were highly accurate in predicting the degree of wax removal. According to the fitted models, the optimal conditions of potassium hydroxide concentration, sodium dodecyl sulfate concentration, and reaction time were $5.08 \%, 3.6 \%$, and $63 \mathrm{~min}$, respectively. The use of an RSM model offers considerable flexibility for practical uses because it allows multiple solutions with any desired level of wax removal.
\end{abstract}

Keywords: Bamboo; Wax layer; Alkali pretreatment; Optimization; Response surface methodology (RSM)

Contact information: a: Department of Interior Materials Engineering, Gyeongnam National University of Science and Technology, Jinju 52725, Korea; b: Division of Environmental Science \& Ecological

Engineering, College of Life Sciences \& Biotechnology, Korea University, Seoul 02841, Korea;

*Corresponding author: lovewood@korea.ac.kr

\section{INTRODUCTION}

Bamboo is a non-wood material with strong historical and traditional use in Korea and other Asian countries. It has been widely used for everyday items such as mats, furniture, and handicrafts, but the advent of mass-produced synthetic plastics in the early 1970s greatly decreased the use of bamboo. Recently, however, the decrease in wood supply has stimulated research on value-added utilization of bamboo, due to its fast growth and high renewability. There are chemical treatments for protecting the green color of fresh bamboo (Chang and Wu 2000a, 2000b; Chang and Yeh 2000, 2001; Chang et al. 2001, 2002a; Wu et al. 2002, 2004; Chung et al. 2005; Wu et al. 2005; Chung et al. 2008, 2009, 2011) and preservative treatments for extending its service life (Lee et al. 2001; Möller and Mild 2019). Bamboo-based composites such as bamboo particleboard and bamboo oriented strand board (Sumardi et al. 2007; Semple et al. 2015; De Almeida et al. 2017; Chung and Wang 2018) are important examples of value-added utilization of bamboo.

A natural siliceous wax layer on the bamboo surface prevents liquid from penetrating the bamboo, decreasing the performance of chemical treatments and the bond 
strength of bamboo composites. Therefore, surface treatments to remove the wax layer are a prerequisite for the various value-added utilizations of bamboo. The water-wettability of the bamboo surface is improved most effectively by irradiation with a hydrogen ion beam (Wada et al. 2003). However, among the available methods for removal of the wax layer, soaking with an aqueous alkali solution is widely used as a simple and economical pretreatment method. Bamboo samples have been pretreated at $80{ }^{\circ} \mathrm{C}$ with $2 \%$ potassium hydroxide (KOH) containing 3\% surfactant for $30 \mathrm{~min}$ (Chang et al. 2002b), and Chang et al. (2002a) pretreated bamboo samples at $80{ }^{\circ} \mathrm{C}$ in $4 \%$ potassium carbonate $\left(\mathrm{K}_{2} \mathrm{CO}_{3}\right)$ and $1 \%$ surfactant mixtures for $30 \mathrm{~min}$ to remove the wax layer on the outer surfaces. Chang and Yeh (2001) pretreated bamboo samples at $80{ }^{\circ} \mathrm{C}$ with a mixture of $2 \% \mathrm{KOH}$ and $3 \%$ sodium lauryl sulfate $\left(\mathrm{NaC}_{12} \mathrm{H}_{25} \mathrm{SO}_{4}\right)$ as an anionic surfactant for 30 min for removing waxes.

This study was performed to select appropriate chemical reagents for removing the wax layer on bamboo culm and to suggest optimal treatment conditions with the selected agents. Response surface methodology (RSM) was used to find the optimized conditions for the wax removal treatment, and the flexibility of the RSM model for practical purposes was discussed.

\section{EXPERIMENTAL}

\section{Materials}

Three-year-old giant timber bamboo (Phyllostachys bambusoides S. et Z.), hachiku bamboo (Phyllostachys nigra var. henosis Stapf), and moso bamboo (Phyllostachys pubescens Mazel) were harvested from the bamboo forest in southern Korea. The fresh bamboo culms were cut into strips with dimensions of $100 \mathrm{~mm}$ (longitudinal) $\times 20 \mathrm{~mm}$ (tangential) and stored at $20{ }^{\circ} \mathrm{C}$ until their moisture contents (MC) reached approximately $12 \%$. All reagents used were of analytical grade and purchased from Sigma-Aldrich.

\section{Methods}

Selection of reagent for wax removal

Wax removal efficiency was evaluated for $3 \%$ solutions of potassium carbonate $\left(\mathrm{K}_{2} \mathrm{CO}_{3}\right)$, potassium hydroxide $(\mathrm{KOH})$, sodium carbonate $\left(\mathrm{Na}_{2} \mathrm{CO}_{3}\right)$, sodium chloride $(\mathrm{NaCl})$, and their mixtures with $1 \%$ sodium dodecyl sulfate $\left(\mathrm{NaC}_{12} \mathrm{H}_{25} \mathrm{SO}_{4}\right)$ as a surfactant. Five samples per treatment combination were put into beakers, and each of the prepared solutions $(1 \mathrm{~L})$ was added into them. The sample to solution ratio was approximately 1:20. The contents were heated at $90{ }^{\circ} \mathrm{C}$ for $1 \mathrm{~h}$ and then carefully rinsed with distilled water. The samples were conditioned to $12 \% \mathrm{MC}$ after the treatment. The wax removal efficacies of the tested chemicals were evaluated by the change in the contact angle of water upon an outer surface of the sample. A $10-\mu \mathrm{L}$ water droplet was placed on the bamboo sample surface with a micropipette, and the contact angle was measured at ambient conditions by a contact-angle meter (OCA25, Dataphysics Instruments GmbH, Filderstadt, Germany) at $0 \mathrm{~s}$ and $20 \mathrm{~s}$ after it was placed onto the bamboo surface (Kwok and Neumann 1999).

\section{Determination of optimal treatment conditions}

With the reagent selected, a series of experiments was designed to find the optimized treatment conditions for wax removal from giant timber bamboo; 15 different combinations were set according to a $2^{3}$ factorial central composite design (Table 1). All 
experiments were performed at $90{ }^{\circ} \mathrm{C}$, and each treatment had five replicates. Each variable was coded by Eq. 1 to simplify the statistical analysis:

$$
C=[R-\{\max (R)+\min (R)\} / 2] /[\{\max (R)-\min (R)\} / 3]
$$

where $C$ is the coded value, and $R$ is the actual value.

The experimental design consisted of eight equally spaced points: one point on a circle of radius $\sqrt{2}$, one point in the design center, and six points on a circle of radius 1.5 . Although a point with radius 2 offers more precise results for modeling, the value of 1.5 instead of $\sqrt{2}$ was chosen to provide easy control of the treatment variables in this experiment. The set of six points on a circle of radius 1.5 allows for efficient estimation of pure quadratic terms (Myers and Montgomery 1995).

Table 1. $2^{3}$ Factorial Central Composite Design of Wax Removal Experiment

\begin{tabular}{|c|c|c|c|c|c|}
\hline \multicolumn{3}{|c|}{ Actual Variables } & \multicolumn{3}{c|}{ Coded Variables } \\
\hline Chemical (\%) & Surfactant (\%) & Time $(\min )$ & Chemical (\%) & Surfactant (\%) & Time (min) \\
\hline 2 & 1 & 20 & -1 & -1 & -1 \\
\hline 6 & 1 & 20 & +1 & -1 & -1 \\
\hline 2 & 3 & 20 & -1 & +1 & -1 \\
\hline 6 & 3 & 20 & +1 & +1 & -1 \\
\hline 2 & 1 & 60 & -1 & -1 & +1 \\
\hline 6 & 1 & 60 & +1 & -1 & +1 \\
\hline 2 & 3 & 60 & -1 & +1 & +1 \\
\hline 6 & 3 & 60 & +1 & +1 & +1 \\
\hline 4 & 2 & 40 & 0 & 0 & 0 \\
\hline 1 & 2 & 40 & -1.5 & 0 & 0 \\
\hline 7 & 2 & 40 & +1.5 & 0 & 0 \\
\hline 4 & 0.5 & 40 & 0 & -1.5 & 0 \\
\hline 4 & 3.5 & 40 & 0 & +1.5 & 0 \\
\hline 4 & 2 & 10 & 0 & 0 & -1.5 \\
\hline 4 & 2 & 70 & 0 & 0 & +1.5 \\
\hline
\end{tabular}

Statistical analysis

Statistical analysis was performed using SAS/Graph® software (Version 6.1, SAS Institute Inc., Cary, NC, USA). The quadratic RSM model was determined at the 0.05 significance level, and three-dimensional response surface plots and contour plots were made using the fitted model.

\section{RESULTS AND DISCUSSION}

\section{Selection of Reagent for Wax Removal}

The measured contact angles of the bamboo samples treated with $3 \%$ solutions of potassium carbonate, potassium hydroxide, sodium carbonate, and sodium chloride, along with their mixtures with $1 \%$ sodium dodecyl sulfate, are shown in Table 2 . The lowest initial contact angle was observed in samples treated with the mixture of potassium hydroxide and sodium dodecyl sulfate, followed by samples treated with the potassium 
hydroxide. Treatment with the mixture of potassium hydroxide and sodium dodecyl sulfate decreased the initial contact angle from $72.8^{\circ}$ to $52.6^{\circ}, 68.8^{\circ}$ to $48.7^{\circ}$, and $69.8^{\circ}$ to $45.7^{\circ}$ in giant timber bamboo, hachiku bamboo, and moso bamboo, respectively. This result indicates that the wax layer of the bamboo epidermis was considerably removed by pretreatment with the mixture of potassium hydroxide and sodium dodecyl sulfate, regardless of bamboo species. In the samples treated with the mixture of potassium hydroxide and sodium dodecyl sulfate, the initial contact angle decreased by $5^{\circ}$ to $10^{\circ}$ in the first $20 \mathrm{~s}$ after wetting. The other reagents were not effective for removing the wax layer, as the initial contact angles of the treated samples were similar to those of the untreated samples for both hachiku bamboo and moso bamboo, although the initial contact angle slightly decreased in giant timber bamboo. In these cases, the contact angle was independent of wetting time for all bamboo species tested; that is, the contact angle was almost constant in the wetting period between $0 \mathrm{~s}$ and $20 \mathrm{~s}$. Based on these results, the mixture of potassium hydroxide and sodium dodecyl sulfate was selected as the chemical combination for wax removal from the bamboo epidermis for further research. The highest wax removal performance of potassium hydroxide is attributed to its highest alkalinity. The $\mathrm{pH}$ of potassium carbonate, potassium hydroxide, sodium carbonate, and sodium chloride solutions were $11.5,13.6,11.5$, and 6.4 , respectively. The alkalinity of other reagents might be not enough to cause considerable wax removal from bamboo species. An increase in alkali concentration was known to perform wax removal from bamboo species better (Wong et al. 2010).

Table 2. Contact Angles of a Water Droplet on the Outer Surface of Bamboo *

\begin{tabular}{|c|c|c|c|c|c|c|}
\hline & \multicolumn{2}{|c|}{ Giant Timber Bamboo } & \multicolumn{2}{|c|}{ Hachiku Bamboo } & \multicolumn{2}{c|}{ Moso Bamboo } \\
\hline Chemical & $\theta_{0 \mathrm{sec}}\left(^{\circ}\right)$ & $\theta_{20 \mathrm{sec}}\left(^{\circ}\right)$ & $\theta_{0 \mathrm{sec}}\left(^{\circ}\right)$ & $\theta_{20 \mathrm{sec}}\left(^{\circ}\right)$ & $\theta_{0 \mathrm{sec}}\left(^{\circ}\right)$ & $\theta_{20 \mathrm{sec}}\left(^{\circ}\right)$ \\
\hline Control & $72.8(1.5)$ & $72.2(1.9)$ & $68.8(1.0)$ & $69.4(1.3)$ & $69.8(1.7)$ & $69.4(1.4)$ \\
\hline $\mathrm{PC}$ & $68.2(3.1)$ & $68.1(2.7)$ & $72.5(1.8)$ & $72.4(1.6)$ & $71.9(2.6)$ & $71.5(2.6)$ \\
\hline $\mathrm{PC}+\mathrm{S}$ & $66.3(1.3)$ & $65.9(1.2)$ & $72.3(1.1)$ & $72.3(1.2)$ & $70.1(1.0)$ & $69.5(1.7)$ \\
\hline $\mathrm{PH}$ & $61.4(5.1)$ & $56.8(5.5)$ & $58.2(4.6)$ & $51.8(5.8)$ & $61.5(3.8)$ & $59.6(2.6)$ \\
\hline $\mathrm{PH}+\mathrm{S}$ & $52.6(6.2)$ & $46.2(8.6)$ & $48.7(6.2)$ & $39.2(5.6)$ & $45.7(6.6)$ & $40.9(5.8)$ \\
\hline $\mathrm{SCA}$ & $67.6(1.7)$ & $67.2(1.8)$ & $71.8(1.7)$ & $72.2(1.3)$ & $69.9(2.5)$ & $69.7(2.5)$ \\
\hline $\mathrm{SCA}+\mathrm{S}$ & $65.7(2.5)$ & $65.5(2.4)$ & $69.6(1.7)$ & $69.3(1.6)$ & $68.4(4.0)$ & $68.0(3.6)$ \\
\hline $\mathrm{SCL}$ & $63.9(3.3)$ & $63.9(3.0)$ & $69.3(1.8)$ & $69.4(1.7)$ & $70.9(1.4)$ & $70.9(1.3)$ \\
\hline $\mathrm{SCL}+\mathrm{S}$ & $65.9(2.8)$ & $66.1(2.7)$ & $67.7(1.2)$ & $66.6(0.9)$ & $69.1(2.4)$ & $68.8(2.2)$ \\
\hline
\end{tabular}

* Values represent the mean of five replicates, and values in parenthesis represent the standard deviation. $\theta_{t \sec }-$ contact angle after $t$ seconds, $\mathrm{PC}$ - potassium carbonate, $\mathrm{PH}$ - potassium hydroxide, SCA - sodium carbonate, SCL - sodium chloride, and S - surfactant

\section{Determination of Optimal Treatment Conditions}

The differences in the contact angle before and after treatment were determined for 15 different treatment conditions using the mixtures of potassium hydroxide and sodium dodecyl sulfate as shown in Table 3. 
Table 3. Differences of Contact Angles of Water Droplet on the Bamboo Surface for Various Treatment Conditions

\begin{tabular}{|c|c|c|c|c|c|c|}
\hline \multicolumn{3}{|c|}{ Actual Variables } & \multicolumn{3}{|c|}{ Coded Variables } & \multirow{2}{*}{$\begin{array}{c}\text { Difference of } \\
\text { Contact } \\
\text { Angles }\left({ }^{\circ}\right) \text { * }\end{array}$} \\
\hline $\begin{array}{c}\mathrm{KOH} \\
(\%)\end{array}$ & $\begin{array}{c}\text { Surfactant } \\
(\%)\end{array}$ & $\begin{array}{l}\text { Time } \\
(\min )\end{array}$ & $\begin{array}{c}\mathrm{KOH} \\
(\%)\end{array}$ & $\begin{array}{c}\text { Surfactant } \\
(\%)\end{array}$ & $\begin{array}{l}\text { Time } \\
(\min )\end{array}$ & \\
\hline 2 & 1 & 20 & -1 & -1 & -1 & 2.34 \\
\hline 6 & 1 & 20 & +1 & -1 & -1 & 1.72 \\
\hline 2 & 3 & 20 & -1 & +1 & -1 & 3.47 \\
\hline 6 & 3 & 20 & +1 & +1 & -1 & 8.23 \\
\hline 2 & 1 & 60 & -1 & -1 & +1 & 7.63 \\
\hline 6 & 1 & 60 & +1 & -1 & +1 & 12.37 \\
\hline 2 & 3 & 60 & -1 & +1 & +1 & 12.75 \\
\hline 6 & 3 & 60 & +1 & +1 & +1 & 18.82 \\
\hline 4 & 2 & 40 & 0 & 0 & 0 & 16.17 \\
\hline 1 & 2 & 40 & -1.5 & 0 & 0 & 4.31 \\
\hline 7 & 2 & 40 & +1.5 & 0 & 0 & 9.30 \\
\hline 4 & 0.5 & 40 & 0 & -1.5 & 0 & 7.57 \\
\hline 4 & 3.5 & 40 & 0 & +1.5 & 0 & 17.43 \\
\hline 4 & 2 & 10 & 0 & 0 & -1.5 & 2.73 \\
\hline 4 & 2 & 70 & 0 & 0 & +1.5 & 16.37 \\
\hline
\end{tabular}

${ }^{*}$ The values represent the differences of the contact angles before and after the treatment.

The efficiency of wax removal tended to increase with increases of the concentrations of potassium hydroxide and sodium dodecyl sulfate and of reaction time. The initial contact angles were used to fit the quadratic RSM model. Equation 2 describes the differences of the contact angles on the bamboo surface in terms of the coded factors,

$$
Y_{1}=5.635+5.674 x_{1}+8.598 x_{2}+14.230 x_{3}-7.774 x_{1}^{2}-5.215 x_{3}^{2}
$$

where $Y_{1}$ is the difference in contact angle $\left(^{\circ}\right)$ before and after the treatment, $x_{1}$ is the coded $\mathrm{KOH}$ concentration, $x_{2}$ is the coded surfactant concentration, and $x_{3}$ is the coded reaction time.

For practical applications, the equation should be in terms of the actual variables. Equation 3 describes the RSM model representing the differences in contact angles in terms of the actual variables,

$$
Y_{2}=-36.405+18.385 a+8.598 b+0.3315 c-1.9435 a^{2}-0.01304 c^{2}
$$

where $Y_{2}$ is the difference in contact angle $\left(^{\circ}\right)$ before and after the treatment, $a$ is the $\mathrm{KOH}$ concentration (\%), $b$ is the surfactant concentration (\%), and $c$ is the reaction time (min).

The fitted models had a coefficient of determination $\left(\mathrm{R}^{2}\right)$ greater than 0.98 , meaning that they were highly accurate in reflecting the degree of wax removal. The equations showed that the concentration of potassium hydroxide affected the wax removal the most, followed by the surfactant concentration and reaction time. No interaction effect of the reagent concentrations and reaction time on wax removal was found at the 0.05 significance level.

The optimal values of potassium hydroxide concentration, sodium dodecyl sulfate concentration, and reaction time determined from the fitted RSM model were 5.08\%, 3.6\%, and $63 \mathrm{~min}$, respectively. However, multiple solutions could be obtained for any desired 
level of wax removal by using the RSM surface plots (Figs. 1 to 3 ). The contour graphs can be applied for simultaneous optimization of several responses. The contour lines represent the same degree of wax removal, and any combination of potassium hydroxide and sodium dodecyl sulfate can be chosen as an optimized solution.

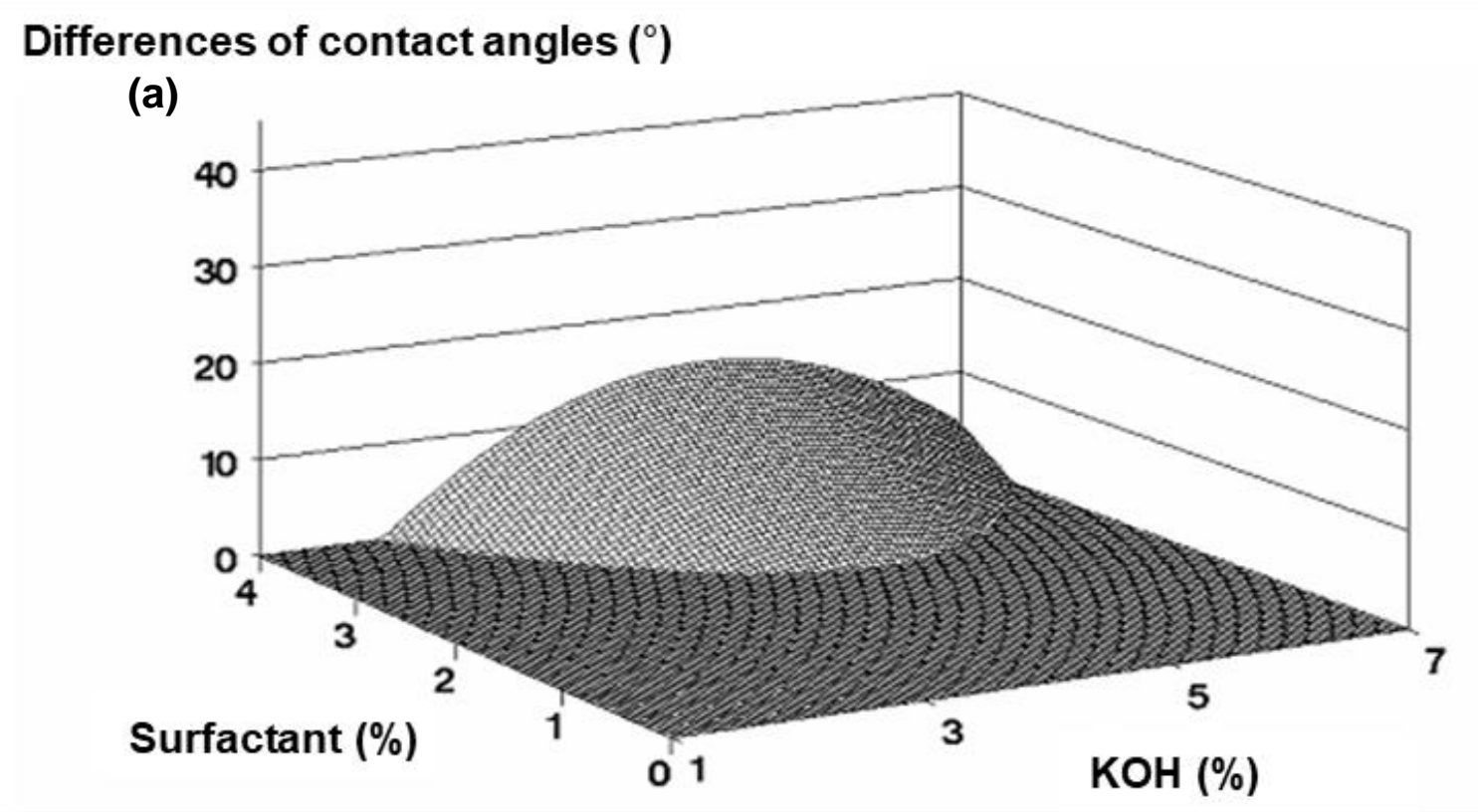

(b)

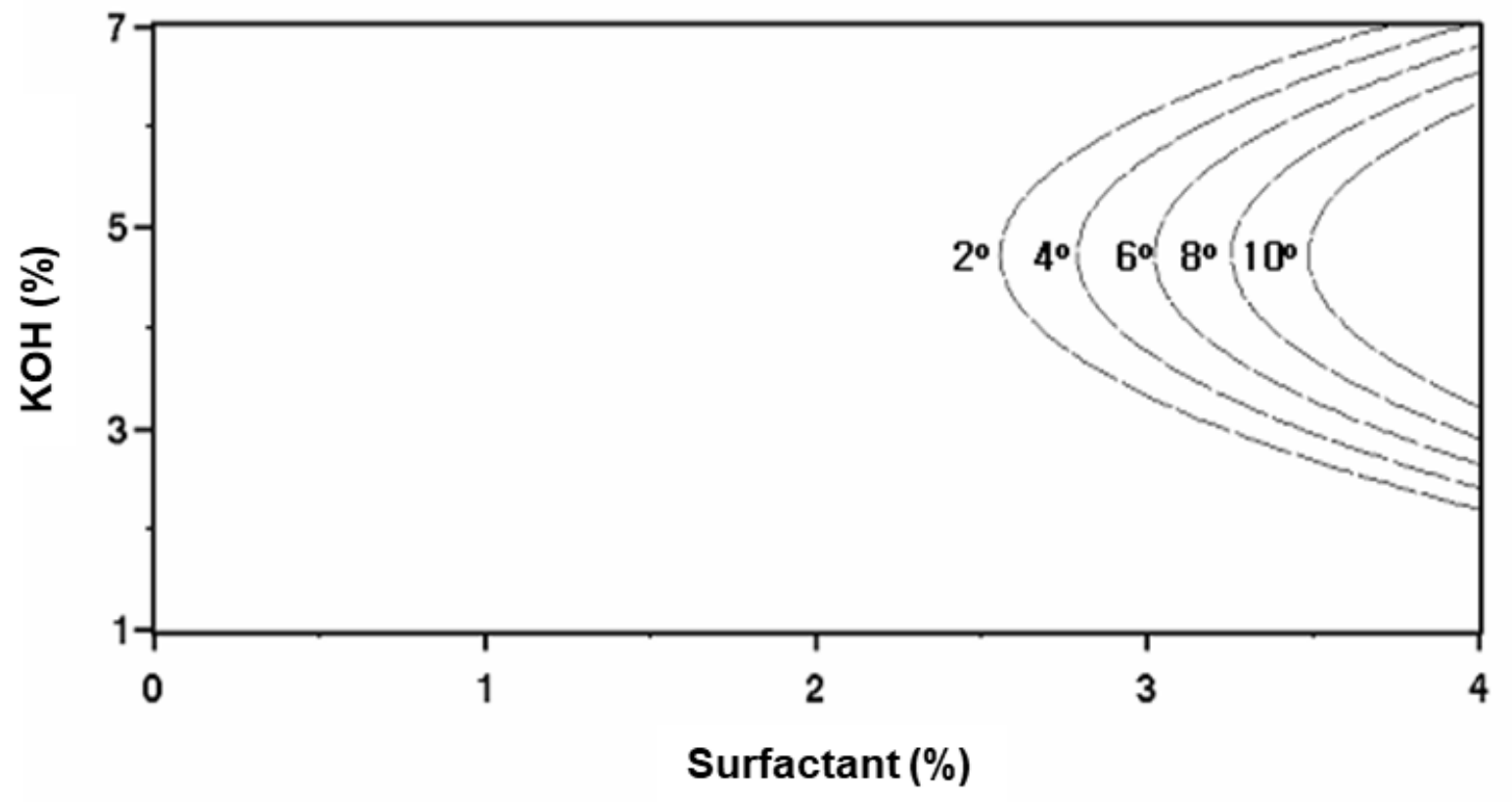

Fig. 1. Difference in contact angle of water droplet on bamboo surface before and after treatment when the reaction time is $20 \mathrm{~min}$ : (a) three-dimensional response surface plot and (b) contour plot 

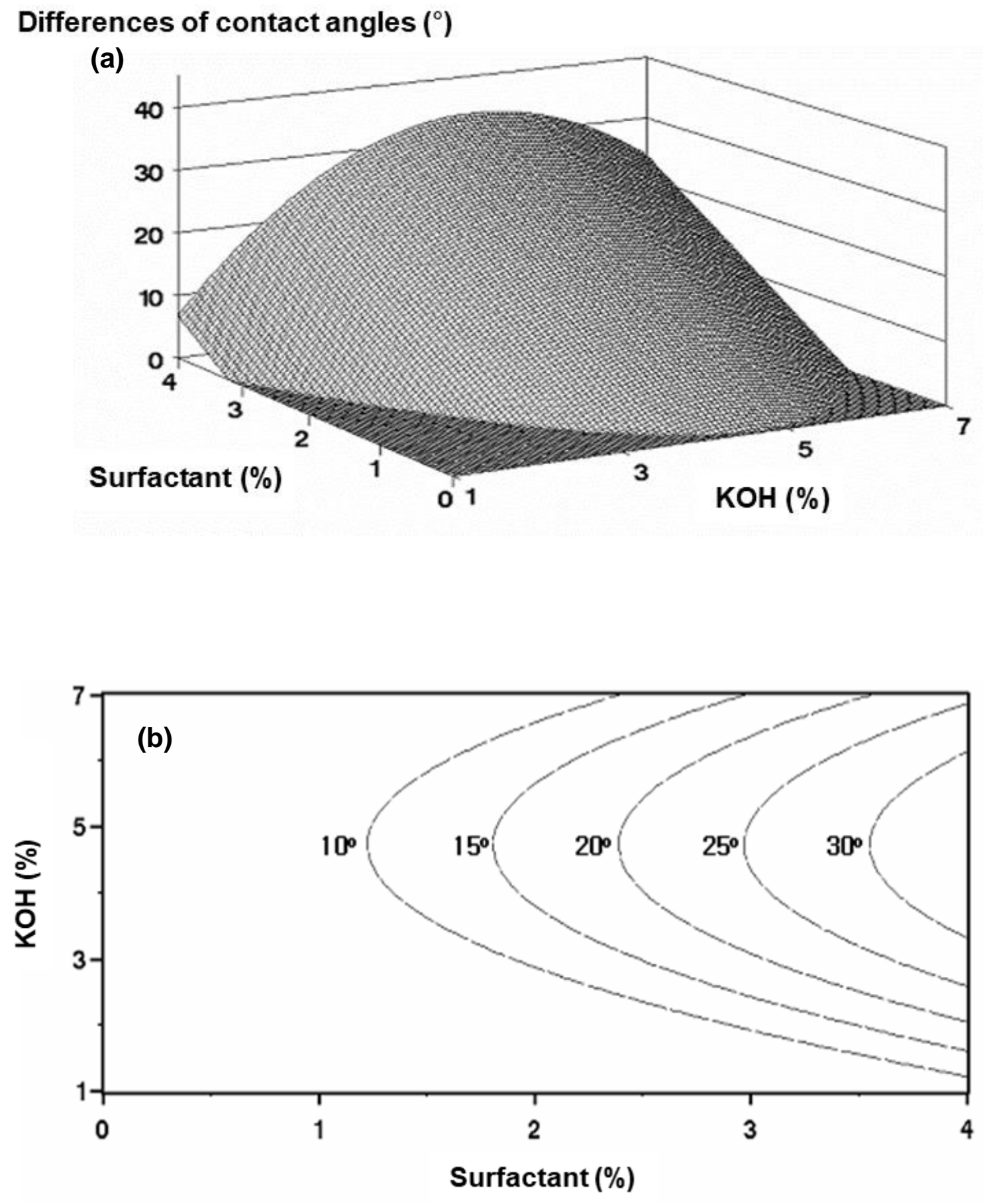

Fig. 2. Difference in contact angle of water droplet on bamboo surface before and after treatment when the reaction time is $40 \mathrm{~min}$ : (a) three-dimensional response surface plot and (b) contour plot 

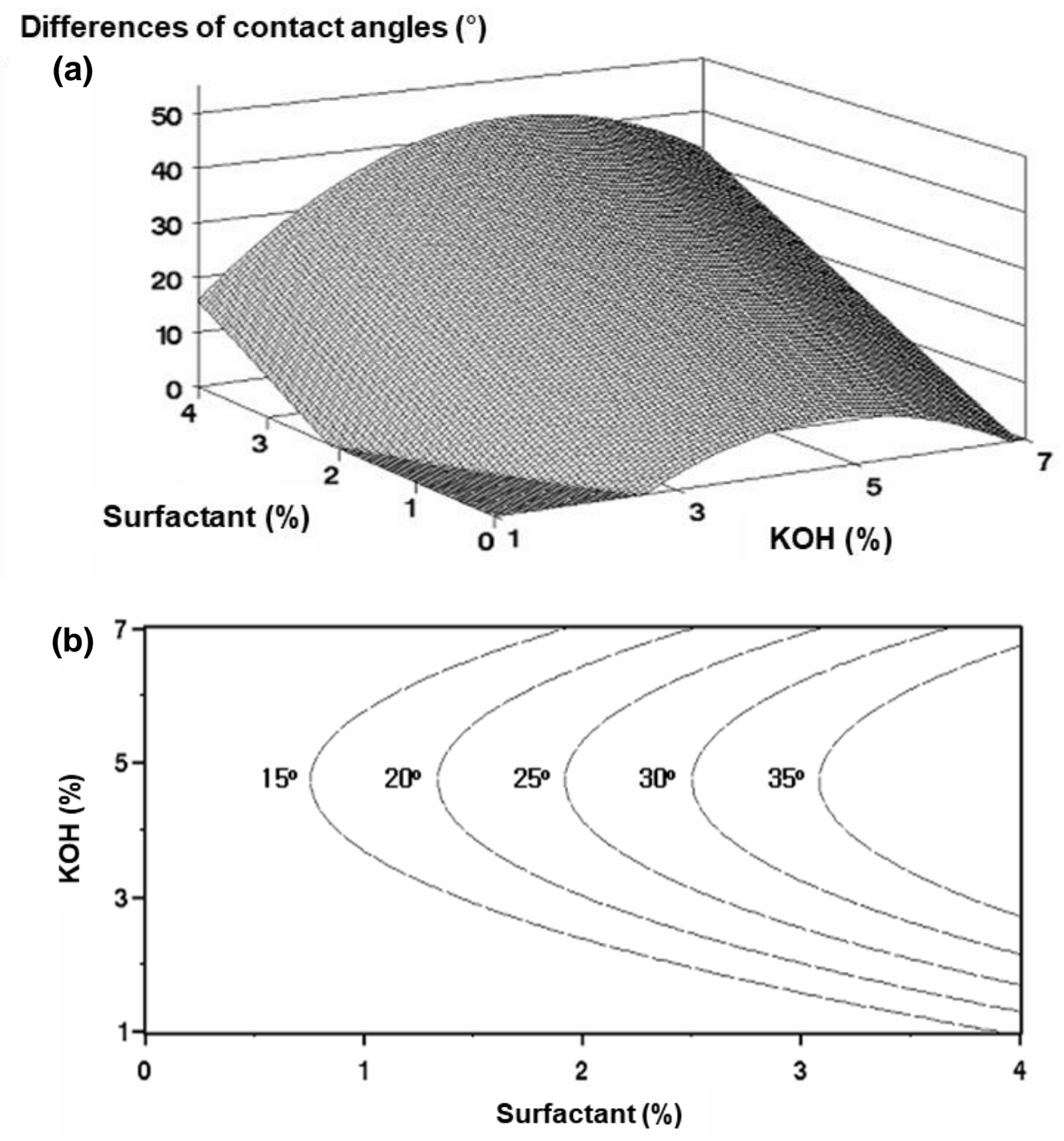

Fig. 3. Difference in contact angle of water droplet on bamboo surface before and after treatment when the reaction time is $60 \mathrm{~min}$ : (a) three-dimensional response surface plot and (b) contour plot

\section{CONCLUSIONS}

1. Among the various chemicals tested, the mixture of potassium hydroxide and sodium dodecyl sulfate was the most effective for removing wax from the bamboo culms.

2. According to the fitted RSM model for determining the optimal treatment conditions, the concentration of potassium hydroxide affected the wax removal the most, followed by surfactant concentration and reaction time. No interaction effect of the reagent concentrations and reaction time on wax removal was found.

3. The optimal values of potassium hydroxide concentration, sodium dodecyl sulfate concentration, and reaction time determined from the fitted RSM model were $5.08 \%$, $3.6 \%$, and $63 \mathrm{~min}$, respectively. Simultaneous optimization of several responses offers considerable flexibility in controlling treatment variables for practical purposes. 


\section{ACKNOWLEDGMENTS}

This study was conducted with the support of Technology Development Program for Agriculture and Forestry and of 'Forest Science \& Technology Projects (Project No. S121010L110000)' provided by the Korea Forest Service.

\section{REFERENCES CITED}

Chang, S.-T., and Wu, J.-H. (2000a). "Green-color conservation of ma bamboo (Dendrocalamus latiflorus) treated with chromium-based reagents," Journal of Wood Science 46, 40-44. DOI: 10.1007/BF00779551

Chang, S.-T., and Wu, J.-H. (2000b). "Stabilizing effect of chromated salt treatment on the green color of ma bamboo (Dendrocalamus latiflorus)," Holzforschung 54(3), 327-330. DOI: 10.1515/HF.2000.055

Chang, S.-T., and Yeh, T.-F. (2000). "Effects of alkali pretreatment on surface properties and green color conservation of moso bamboo (Phyllostachys pubescens Mazel)," Holzforschung 54(5), 487-491. DOI: 10.1515/HF.2000.082

Chang, S.-T., and Yeh, T.-F. (2001). "Protection and fastness of green color of moso bamboo (Phyllostachys pubescens Mazel) treated with chromium-based reagents," Journal of Wood Science 47, 228-232. DOI: 10.1007/BF01171226

Chang, S.-T., Wu, J.-H., and Yeh, T.-F. (2002a). "Effects of chromated-phosphate treatment process on the green color protection of ma bamboo (Dendrocalamus latiflorus)," Journal of Wood Science 48, 227-231. DOI: 10.1007/BF00771372

Chang, S.-T., Yeh, T.-F., and Wu, J.-H. (2001). "Mechanisms for the surface colour protection of bamboo treated with chromated phosphate," Polymer Degradation and Stability 74(3), 551-557. DOI: 10.1016/S0141-3910(01)00192-6

Chang, S.-T., Yeh, T.-F., Wu, J.-H., and Hon, D. N.-S. (2002b). "Reaction characteristics on the green surface of moso bamboo (Phyllostachys pubescens Mazel) treated with chromated phosphate," Holzforschung 56(2), 130-134. DOI: 10.1515/HF.2002.022

Chung, M.-J., and Wang, S.-Y. (2018). "Mechanical properties of oriented bamboo scrimber boards made of Phyllostachys pubescens (moso bamboo) from Taiwan and China as a function of density," Holzforschung 72(2), 151-158. DOI: 10.1515/hf2017-0084

Chung, M.-J., Cheng, S.-S., and Chang, S.-T. (2008). "Environmental-benign methods for the color protection of stripe long-shoot bamboo (Bambusa dolichoclada) culms," Building and Environment 43(5), 745-750. DOI: 10.1016/j.buildenv.2007.01.014

Chung, M.-J., Cheng, S.-S., and Chang, S.-T. (2009). "Environmentally benign methods for producing green culms of ma bamboo (Dendrocalamus latiflorus) and moso bamboo (Phyllostachys pubescens)," Journal of Wood Science 55, 197-202. DOI: 10.1007/s10086-008-1014-0

Chung, M.-J., Cheng, S.-S., Lee, C.-J., and Chang, S.-T. (2011). "Novel environmentallybenign methods for green-colour protection of bamboo culms and leaves," Polymer Degradation and Stability 96(4), 541-546. DOI:

10.1016/j.polymdegradstab.2011.01.008

Chung, M.-J., Wu, J.-H., and Chang, S.-T. (2005). "Green colour protection of makino bamboo (Phyllostachys makinoi) treated with ammoniacal copper quaternary and copper azole preservatives," Polymer Degradation and Stability 90(1), 167-172. DOI: 
10.1016/j.polymdegradstab.2005.03.005

De Almeida, A. C., De Araujo, V. A., Morales, E. A. M., Gava, M., Munis, R. A., Garcia, J. N., and Barbosa, J. C. (2017). "Wood-bamboo particleboard: Mechanical properties," BioResources 12(4), 7784-7792. DOI: 10.15376/biores.12.4.7784-7792

Lee, A. W. C., Chen, G., and Tainter, F. H. (2001). "Comparative treatability of moso bamboo and southern pine with CCA preservative using a commercial schedule," Bioresource Technology 77(1), 87-88. DOI: 10.1016/S0960-8524(00)00145-0

Kwok, D. Y., and Neumann, A. W. (1999). "Contact angle measurement and contact angle interpretation," Advances in Colloid and Interface Science 81(3), 167-249. DOI: 10.1016/S0001-8686(98)00087-6

Möller, R., and Mild, G. (2019). "Protection of moso bamboo (Phyllostachys pubescens) materials against fungal decay and discolouration by treatment with wood preservatives," European Journal of Wood and Wood Products 77, 139-145. DOI: 10.1007/s00107-018-1371-3

Myers, R. H., and Montgomery, D. C. (1995). Response Surface Methodology: Process and Product Optimization Using Designed Experiments, John Wiley \& Sons, Inc., New York, NY, USA.

Semple, K. E., Zhang, P. K., and Smith, G. D. (2015). "Hybrid oriented strand boards made from moso bamboo ((Phyllostachys pubescens Mazel) and aspen (Populus tremuloides Michx.): Species-separated three-layer boards," European Journal of Wood and Wood Products 73, 527-536. DOI: 10.1007/s00107-015-0914-0

Sumardi, I., Ono, K., and Suzuki, S. (2007). "Effect of board density and layer structure on the mechanical properties of bamboo oriented strandboard," Journal of Wood Science 53(6), 510-515. DOI: 10.1007/s10086-007-0893-9

Wada, M., Nishigaito, S., Flauta, R., and Kasuya, T. (2003). "Modification of bamboo surface by irradiation of ion beams," Nuclear Instruments and Methods in Physics Research Section B: Beam Interactions with Materials and Atoms 206, 557-560. DOI: 10.1016/S0168-583X(03)00822-X

Wong, K. J., Yousif, B. F., and Low, K. O. (2010). "The effects of alkali treatment on the interfacial adhesion of bamboo fibres," Proceedings of the Institution of Mechanical Engineers, Part L: Journal of Materials: Design and Applications 224, 139-148. DOI: $10.1243 / 14644207 J M D A 304$

Wu, J.-H., Chung, M.-J., and Chang, S.-T. (2004). "Evaluation of the effectiveness of alcohol-borne reagents on the green colour protection of makino bamboo (Phyllostachys makinoi)," Polymer Degradation and Stability 83(3), 473-479. DOI: 10.1016/j.polymdegradstab.2003.08.014

Wu, J.-H., Chung, M.-J., and Chang, S.-T. (2005). "Green color protection of bamboo culms using one-step alkali pretreatment-free process," Journal of Wood Science 51, 622-627. DOI: 10.1007/s10086-005-0698-7

Wu, J.-H., Wu, S.-Y., Hsieh, T.-Y., and Chang, S.-T. (2002). "Effects of copperphosphorous salt treatments on green colour protection and fastness of ma bamboo (Dendrocalamus latiflorus)," Polymer Degradation and Stability 78(2), 379-384. DOI: 10.1016/S0141-3910(02)00190-8

Article submitted: June 23, 2020; Peer review completed: Peer review completed: Aug. 23, 2020; Revised version received and accepted: Sept. 4, 2020; Published: September $11,2020$.

DOI: $10.15376 /$ biores.15.4.8202-8211 